On Sept. 7 th I removed with the forceps a trau. matic diphtheritic membrane from the uvula and palate, which was considerably interfering with the breathing. Had I not known the history of the case and only seen the patient for the first time on this occasion I should have had no hesitation in stating that it was a very bad case of diphtheria. I took some of the membrane to Dr. John Biernacki, the medical superintendent of the Plaistow Fever Hospital, who said it looked like an ordinary case of diphtheria until I gave him the history of the case. He kindly had the specimen examined for me with negative results. An ordinary gargle of biborate of soda removed the false membrane and the mouth was quite clear and in its normal condition by the tenth day. The patient was decidedly better, but was complaining of intense pain all over the region of the stomach, with a sensation of choking and suffocation. The temperature and pulse were normal. Four days later (Sept. 11th) he felt sick and said he had a lump coming up in his throat, and he thrust his fingers as far down as he could to bring it up. What he brought up frightened him. This vomit appeared to me from its shape to be a complete cast of the whole of the cesophagus and stomach. After floating it out in water and examining it, I told his wife to save it and place it in a small glass jar. She unfortunately let the basin fall on the floor and smashed it, but gathered it up as well as she could, and I have placed it in spirit. On the next day vomiting again set in, the vomit being mixed with bright arterial blood. Iced. milk, sugar dissolved in cold water, and minim doses of dilute liq. ferri perchlor. were given three or four times daily. The patient had very little sickness subsequently, and seemed to be in a fair way toward recovery. His diet was restricted to milk and oatmeal flour, with other like soft and pulpy foods.

On Oct. 5th the patient walked to the surgery for the first time since taking the acid, and stated that he was feeling quite himself again, and that he hoped shortly to resume his ordinary work. He asked if he might have a little more substantial food. I gave him permission and told him to be very restricted in his diet. On the 7 th he called again, stating that he had had a relapse and was romiting everything he took in the shape of food. He also informed me that he had taken a mutton chop, greens, and potatoes. I examined the urine; its specific gravity was 1035 and it was acid in reaction, no sugar or albumin being present. The heart sounds were normal and the pulse-rate was 84 and regular in force and rhythm. There was hyperresonance over the upper part of the left lung.

The patient expressed a desire to go to a hospital and see if anything further could be done for him. $\mathrm{He}$ was admitted to Charing Cross Hospital, an operation was performed on Nov. 2nd, and he unfortunately died from shock.

Plaistow, E.

\section{A NOTE ON PLAGUE BACILLI IN AN UNUSUAL SITUATION IN THE BODY.}

BY J. H. Sheldon, M.B. Lond., \&C., DISTRICT MEDICAL OFFICER, BURMA RAILWAYS, INSEIN, BURMA.

AT 8.30 A.M. on Nov. 29th, 1913, I received information that an adult Burman male was in a dying condition, after an illness of 36 hours only, and that during the past hour convulsions and head retrac tion had been present. The sub-assistant suigeon was sent to see the man, and instructed to obtain slides of the cerebro-spinal fluid in addition to those of the blood, as it seemed possible that the case might be one of epidemic cerebro-spinal meningitis. $\mathrm{He}$ arrived at 9 A.M. to find the patient dead. A superficial examination of the body failed to discover any bubo or other gross lesion.

Specimens of peripheral blood were stained with gentian-violet and of the cerebro-spinal fluid with carbol-fuchsin, and examination of the slides revealed the presence of typical plague bacilli in small numbers; the slides of the cerebro-spinal fluid simply swarmed with them.

I have to thank the chief medical officer of the Burma Railways for his permission to publish the case.

Insein, Burma.

\section{Aflevital Sorieties.}

\section{ROYAL SOCIETY OF MEDICINE.}

\section{SECTION OF OPHTHALMOLOGY. \\ Exhibition of Cases.-Retinitis of Pregnanoy.}

A MEETING of this section was held on June 9th, Mr. PrIEstrey SuIth, the President, being in the chair.

The following cases were shown :-

Mr. A. O. HudSON : A case of Sympathetic Ophthalmitis treated by salvarsan and neosalvarsan. It was regarded as an undoubted case of the condition, and seemed a genuine cure.

Mr. J. S. Hosford: Two cases of the Albuminuric Retinitis of Pregnancy.

Mr. C. N. ATLEE : Coloboma of the Iris in mother and child.

Mr. Charles WraY : Bony Growth in the Frontal Sinus. In cases of retrobulbar neuritis suspected to be of sphenoidal origin, he advocated making the patient spend some time with the face downwards, with a view to facilitating drainage from the sphenoidal and posterior ethmoidal cells.-Mr. W. T. Holmes SPICER discussed the case.

Mr. J. HERBERT FISHER read a paper on Retinitis of Pregnancy. He had not included in the title the term "albuminuric," as he wished to lead his hearers away from the idea that the acute retinal changes were the results of the kidney disorder. Obstetricians now no longer explained the albuminuria of pregnancy as the result of obscure reflex effects of the gravid uterus upon the kidneys, or by mechanical pressure on the ureters. They attributed it, with eclampsia and pathological vomiting of pregnancy, to toxæmic products in the circulation. Eclampsia could not be predicated by any examination of the urine; the effects were especially seen in the quality of the blood and in the blood-vessel walls. In fatal cases of eclampsia, hæmorrhages of brain and necrotic changes in the liver were often found, and albuminuria was an effect of the disease on the kidney, not the cause. In the retinitis of pregnancy the condition of retina was different from that in albuminuric retinitis, as also was its sequel. Syncytiotoxins-products of the disintegration of the syncytium cells-had been found in these cases, and these cell immediately connected the foetal with the maternal structures. Mr. Fisher proceeded to give particulars of a series of typical cases of the condition which bad been under his care. In one fatal case Mr. A. C. Hudson made a pathological examination on the day after death, and found the coats of the eye in situ. There was some cedema of the nerve head, and in the nasal quadrant of the retina were two large hæmorrhages. The microscope showed the sclera and nerve sheaths to be normal, the chief pathological changes being in the large choroidal arteries, many of which showed gross endarteritis, causing in some instances obliteration of the vessel lumen. Some of the choroidal arteries were normal. Similar pathological changes were found in sections of posterior ciliary arteries surrounding the optic nerve behind the eyeball. Bruch's membrane was everywhere intact and the retinal pigment normal. The retina and optic nerve head showed evidence 